\title{
Reporting participation rates in studies of non- pharmacological interventions for patients with chronic obstructive pulmonary disease: a systematic review
}

\author{
Ratna Sohanpal ${ }^{1 *}$, Richard Hooper ${ }^{1}$, Rachel Hames ${ }^{1}$, Stefan Priebe ${ }^{2}$ and Stephanie Taylor ${ }^{1}$
}

\begin{abstract}
Background: Pulmonary rehabilitation (PR) and self-management (SM) support programmes are effective in the management of patients with chronic obstructive pulmonary disease (COPD), but these interventions are not widely implemented in routine care. One reason may be poor patient participation and retention. We conducted a systematic review to determine a true estimate of participation and dropout rates in research studies of these interventions.

Methods: Studies were identified from eight electronic databases including MEDLINE, UK Clinical Trial Register, Cochrane library, and reference lists of identified studies. Controlled clinical trial studies of structured SM, PR and health education (HE) programmes for COPD were included. Data extraction included 'participant flow' data using the Consolidated Standards of Reporting Trials (CONSORT) statement and its extension to pragmatic trials. Patient 'participation rates' (study participation rate (SPR), study dropout rate (SDR) and intervention dropout rate (IDR)) were calculated using prior participation definitions consistent with CONSORT. Random effects logistic regression analysis was conducted to examine effects of four key study characteristics (group vs. individual treatment, year of publication, study quality and exercise vs. non-exercise) on participation rates.
\end{abstract}

Results: Fifty-six quantitative studies (51 randomised controlled trials, three quasi-experimental and two before-after studies) evaluated PR ( $n=31), S M(n=21)$ and HE $(n=4)$ programmes. Reports of participant flow were generally incomplete; 'numbers of potential participants identified' were only available for $16 \%$, and 'numbers assessed for eligibility' for only $39 \%$ of studies. Although 'numbers eligible' were better reported $(77 \%)$, we were unable to calculate SPR for $23 \%$ of studies. Overall we found 'participation rates' for studies $(n=43)$ were higher than previous reports; only $19 \%$ of studies had less than 50\% SPR and just over one-third (34\%) had a SPR of 100\%; SDR and IDR were less than or equal to $30 \%$ for around $93 \%$ of studies. There was no evidence of effects of study characteristics on participation rates.

(Continued on next page)

\footnotetext{
*Correspondence: r.sohanpal@qmul.ac.uk

${ }^{1}$ Centre for Primary Care and Public Health, Blizard Institute, Barts and The London School of Medicine and Dentistry, Queen Mary University of London, 58 Turner Street, London E1 2AB, UK

Full list of author information is available at the end of the article
} 
(Continued from previous page)

Conclusion: Unlike previous reports, we found high participation and low dropout rates in studies of PR or SM support for COPD. Previous studies adopted different participation definitions; some reported proportions without stating definitions clearly, obscuring whether proportions referred to the study or the intervention. Clear, uniform definitions of patient participation in studies are needed to better inform the wider implementation of effective interventions.

Keywords: Patient participation, Patient dropouts, Randomised controlled trial, Controlled clinical trial, Chronic obstructive pulmonary disease, Self-care, Self-management

\section{Background}

Chronic obstructive pulmonary disease (COPD) is a large and increasing public health problem. The disease is expected to be the third leading cause of death by 2020 [1], and is already the most costly respiratory disease in Europe, estimated at $€ 38.7$ billion annually [2]. In the UK, COPD affects 2.8 million people although only 0.8 million are diagnosed with the condition [3]. COPD is an irreversible, potentially disabling, lung disease characterised by fatigue and breathlessness and is associated with episodic 'exacerbations' $[4,5]$ that lead to unscheduled health care [6]. An individual with COPD may experience significant functional and psychological limitations disrupting their normal routine and further preventing adherence to medical regimes, dietary changes, exercise and smoking cessation, which can further worsen the condition [3].

Pharmacological treatment only constitutes part of COPD care. Non-pharmacological interventions, such as pulmonary rehabilitation (PR) including patient education, exercise training, psychosocial support and nutritional intervention complement pharmacological therapy [7]. Self-management (SM) programmes have been promoted as another non-pharmacological intervention for helping people with chronic conditions [8]. Self-management refers to an 'individual's ability to manage symptoms, treatment, physical and psychosocial consequences and lifestyle changes inherent in living with a chronic condition. Efficacious self-management encompasses ability to monitor one's condition and to effect the cognitive, behavioural and emotional responses necessary to maintain a satisfactory quality of life' [9]. The aim of a PR programme is to reduce symptoms, improve functional performance, increase participation and reduce health care costs [10]. Using Bourbeau's [11] definition, SM programmes are aimed at teaching the skills needed to perform a specific medical regimen and to achieve health behaviour modification. National health policy guidelines and charities strongly support and recommend the delivery of PR, and provision of SM education and support to help patients with COPD to better manage their condition $[3,6]$ and reduce cost to health services. There is a huge need amongst patients for more education on the disease, management of breathlessness and exacerbations $[3,12]$.
Despite this, a large number of people are unable to access these interventions [13,14]. Although there is evidence of considerable benefit from PR [14,15], only 1 to $2 \%$ of patients are able to access PR programmes because of patient factors, lack of referral from primary care practitioners and lack of infrastructure for provision of PR [14]. In a recent review Bjoernshave [15] questioned whether this benefit could be extrapolated to the entire PR target population as the patients in studies (including 26 articles) were not representative of the target populations. There is also limited implementation of SM programmes for COPD patients in practice. This may be because of the limited evidence of effectiveness of studies of SM programmes for COPD patients $[13,16]$. Effing's review [16] noted that synthesising evidence of effectiveness of SM from studies was difficult due to heterogeneity in interventions, COPD populations, follow-up times and outcome measures. Another reason for lack of implementation could be the poor patient participation and retention frequently reported in the literature on such interventions [6]. Reduced patient participation or high attrition in studies of PR or SM programmes for COPD patients may affect the generalisability of the study findings to the target population.

There are varied reports of poor participation and high dropout rates amongst studies. Studies report that only about $34 \%$ of participants attend after being referred to PR [17] and uptake figures of between 33\% and 39\% have been reported from COPD outpatient clinics [18]. A recent review (including 11 articles) [19] reported that the proportion of referred participants who failed to attend PR at all ranged from $8.3 \%$ to $49.6 \%$, and the proportion of PR dropouts ranged from $9.7 \%$ to $31.8 \%$. Our own study of a COPD disease-specific SM programme [20] identified poor study participation (only 23\%). Attrition may also be a problem but only one study out of fourteen in a review [16] of COPD SM education reported a dropout rate $(30.4 \%)$.

Furthermore, we found large discrepancies between our calculation of study participation rates in some studies [21-23] and those reported by other authors [24,25]. Other studies report participation rates in interventions based on different stages of participant flow before 
recruitment, for example, participation rates calculated from numbers referred into the study [17] or from the numbers screened for the study [26]. In addition, it is unclear from some studies [18,24] which level of participant flow was used to calculate the participation or dropout rate and whether the proportion reported refers to the study or the intervention. This lack of uniformity or clarity all leads to further confusion about actual patient participation rates in studies and interventions.

To address the apparent problem of poor participation and retention, and to identify ways it could be improved, we undertook a systematic review to identify actual levels of participation and attrition reported in randomised and non-randomised studies evaluating non-pharmacological interventions providing self-management support to COPD patients. We hypothesised that the following study characteristics, recruitment process, patient characteristics, intervention characteristics and study quality may influence study participation rates and used random effects logistic regression analysis to explore this.

\section{Methods}

The search

A comprehensive search strategy was developed from other SM systematic reviews (COPD SM education, uptake of cardiac rehabilitation, SM in musculoskeletal pain) $[8,16,27,28], \mathrm{MeSH}$ headings and free text words were used. Relevant studies were identified from searching eight electronic biomedical science databases, and UK Clinical Trial Research registers (1984 to January 2011). We also searched the Cochrane library for systematic and meta-analysis reviews. The reference lists of all identified reviews, and published and unpublished grey reports by organisations that develop and deliver SM programmes for COPD patients in the UK were examined for relevant studies. Only English language papers were included. Additional file 1 presents details on the search strategy and the terms searched.

\section{Study selection criteria}

We included all randomised controlled trials (RCTs), as well as non-randomised studies including beforeafter studies. Interventions included structured selfmanagement (SM) programmes, pulmonary rehabilitation (PR) programmes, self-care (SC) programmes and health education (HE) programmes for adults with COPD. Interventions could be either group-based or targeted at individuals and conducted in any setting, for example, outpatients, inpatients, participant's home, GP surgery, community, or remote (web-based or telephone) or a combination of these settings. Intervention delivery could be by a health professional, or a trained lay person or both. Conference abstracts, surveys and interventions that only included exercise and only SM plans or action plans were excluded.

We obtained full papers of studies identified as potentially eligible based on titles and abstracts. The full copies of the potentially eligible papers were obtained to assess whether the studies met the pre-specified inclusion criteria. If additional information was needed, we contacted the corresponding authors of the study.

\section{Definitions of participation}

For the purpose of the review, we adopted the following definitions (Figure 1):

- 'Study participation' - eligible patients taking part in a study of pulmonary rehabilitation (PR) or selfmanagement $(\mathrm{SM})$ or health education (HE) intervention and 'study participants' - patients that take part in the study.

- 'Study non-participation'- not taking part in a study of PR or SM or HE intervention and 'study nonparticipants' - patients who do not take part in the study.

- The 'study participant' in the intervention arm of the study can be subdivided into an 'attender' - one who is exposed to at least part of the intervention (for example, attends at least one session) and a 'non-attender' - one who is not exposed to any part of the intervention (for example, does not attend any sessions of the intervention).

- The 'attenders' can be further divided into 'intervention dropouts' - those who drop out from the intervention and 'intervention completers' those who complete the intervention.

- 'Study completer' - A 'non-attender,' 'intervention dropout' or 'intervention completer' who completes the study.

- 'Study dropout' - A 'non-attender,' intervention dropout' or 'intervention completer' who withdraws or is lost to follow-up from the study.

\section{Quality assessment}

We included studies of any quality since we were interested in examining whether higher participation rates tended to be reported in higher quality studies. We appraised the quality of both randomised and nonrandomised (including before-after) studies using the criteria generated by Downs and Black [29]. The Downs and Black checklist for quality assessment was selected as it has been developed to use with both randomised and non-randomised studies and is recommended as being suitable for use in systematic reviews [30,31]. Validity and reliability on the original version of the checklist was conducted by experienced epidemiologists and statisticians and a revised version produced [29,31]. Further 


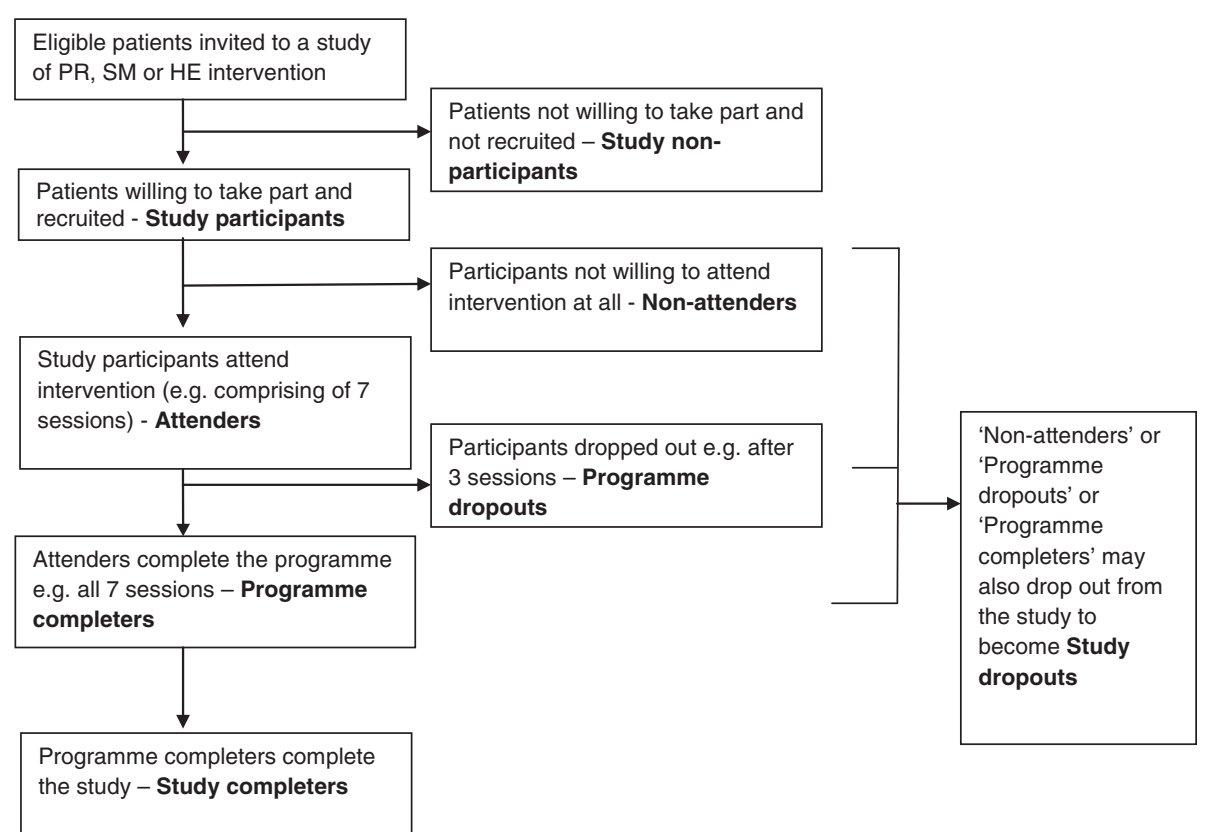

Figure 1 Illustration of patient participation definitions.

assessment of the revised checklist showed that Quality Index had high internal consistency, good test-retest $(\mathrm{r}=0.88)$ and inter-rater $(\mathrm{r}=0.75)$ reliability and good face and criterion validity (0.90) [29].

The checklist allows an overall score for study quality to be reported as well as scores for each of the subscales. The question on power was simplified to a simple check whether the study had conducted a statistical power calculation. The maximum score achievable for each of the subscales was: 11 for reporting, 3 for external validity (an area which has been ignored in all checklists of RCTs), 7 for internal validity - bias in the measurement of the intervention and outcomes, and 6 for internal validity confounding (selection bias), totalling to maximum score of 27.

\section{Data extraction}

A data extraction form was developed and piloted for particular questions to be addressed by the review, and final versions were used to compile summary tables of the data and quality classification. Data extraction included study characteristics (study design, study setting, study eligibility criteria, recruitment process), population characteristics, intervention characteristics, definition of intervention completion, and study outcomes that included participation data.

The patient participation data (before and after recruitment) was extracted from studies by referring to the Consolidated Standards of Reporting Trials (CONSORT) participant flow diagram [32] and the checklist suggested by extension of the CONSORT statement for reporting of pragmatic trials [33]. We extracted the following data, 'numbers of potential participants identified' 'numbers assessed for eligibility', 'numbers eligible ${ }^{\text {a, }}$ 'numbers included (and randomised or not randomised)' to all intervention groups, 'numbers received allocated intervention', 'numbers did not receive allocated intervention', 'numbers lost to follow-up,' 'numbers discontinued intervention', and 'numbers analysed for the primary outcomes'.

A second reviewer checked extraction and calculation of participation rate data from $10 \%$ of the studies sampled at random using a web-based random integer generator [34].

\section{Data analysis}

Calculation of patient 'participation rates' from the extracted participation data was based on the adopted definitions (Figure 2). The study participation rate (SPR) was calculated based on 'numbers included in study' divided by 'numbers eligible'. This method of calculation for SPR is consistent with wording used in extension of the CONSORT statement for reporting of pragmatic trials '... numbers were eligible for study of whom (\%) agreed to participate' [33]. Glasgow [35] also recommended expanding the criteria in the original CONSORT statement to include eight items on external validity, one of which was 'report the participation rate among those eligible'.

For studies that reported both the number of eligible people and the number who were finally included, we determined participation rate with a $95 \%$ confidence interval calculated using a score method with a continuity 


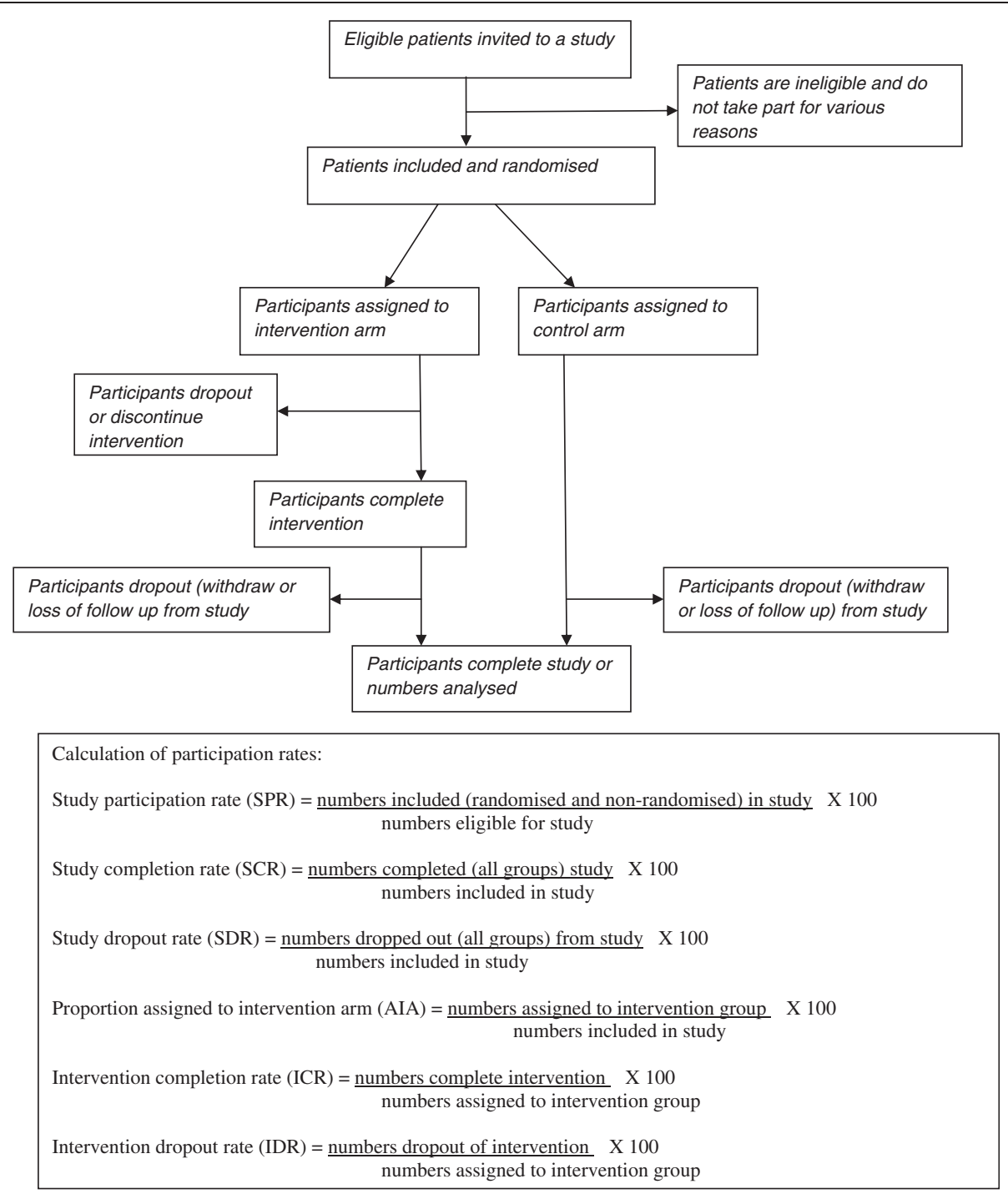

Figure 2 Calculation of participation rates.

correction [36]. We used random effects logistic regression, with participation of each individual as a binary outcome and a random effect of study, to estimate the effects of different study characteristics on participation rates. This amounts to a meta-regression of study results, and allows studies to be included even if their estimated participation rate is $100 \%$.

Because of the relatively small number of studies with complete data, we chose to limit ourselves to looking at four study characteristics: year of publication (linear effect per year), quality score (linear effect per scale point), exercise vs. non-exercise intervention, and group vs. individual treatment (divided into three categories: individual, combined group and individual, and group). Only studies with complete data were included. There was heterogeneity between studies in COPD severity, but this variable was inconsistently reported and difficult to categorise, so was not selected for inclusion. Results are reported as adjusted odds ratio from a multivariable regression model including all four study characteristics.

Comparisons of what was reported by studies before and after publication of the CONSORT guidelines were made using chi-squared tests (or Fisher's exact test where any expected frequency was $<5$ ).

\section{Results}

We identified 3828 studies from the database search and 13 additional studies from other sources (Figure 3). After screening, 56 quantitative studies met our inclusion criteria, 51 RCTs, three quasi-experimental studies and two before-after studies. Thirty-one studies evaluated PR programmes, twenty-one evaluated SM programmes, and four studies evaluated HE programmes. 


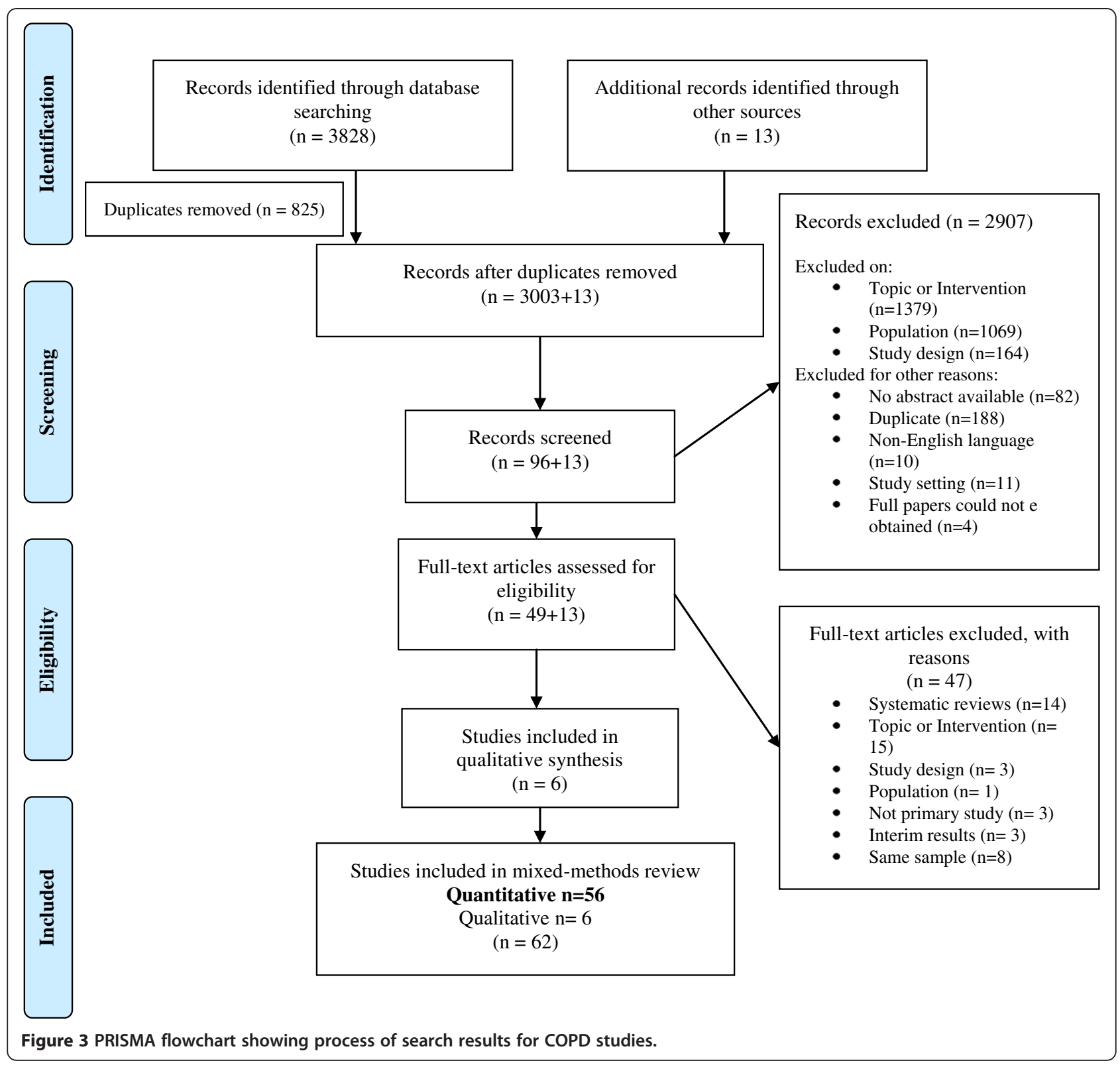

Study quality was variable. The overall quality of study reporting was good (9.9), external validity was low (1.3), internal validity was better amongst studies but, more bias was present in selection of study subjects (3.6) in comparison to bias in the measurement of the intervention and outcome (4.8). Less than half of the studies had conducted a power calculation. There was no clear pattern observed from the quality assessment that high quality studies had higher participation rates. The second reviewer checked a randomly selected $10 \%$ of data extractions and there was 100\% agreement between the two reviewers.

\section{Reporting of participation data and calculation of participation rate}

Additional file 2 provides information on patient participant flow ('number of potential participants identified, 'numbers assessed for eligibility,' 'numbers eligible' for study, 'numbers included (randomised or nonrandomised)' to all intervention groups, 'numbers lost to follow-up', and 'numbers discontinued intervention') and patient 'participation rates' - study participation rate (SPR), study dropout rate (SDR) and intervention dropout rate (IDR) by interventions of interest. Participant flow was poorly reported in all studies. Only nine 
(16\%) studies reported 'numbers of potential participants identified' (4/31 PR, 4/21 SM and 1/4 HE) and twenty-two (39\%) studies reported 'numbers assessed for eligibility' (12 PR and 10 SM). 'Numbers eligible' by studies was better reported, 43 (77\%) studies, (21 PR, 19 $\mathrm{SM}$ and $3 \mathrm{HE}$ ). Fifty-six studies reported 'numbers included (both randomised and non-randomised)' in study, out of five non-randomised studies, two were before-after studies without a control group. Only seven (13\%) studies recorded participant flow numbers right up to participant recruitment. Forty-one (73\%) studies were published after the CONSORT statement in 2001. Better reporting of participant flow was seen in studies published in and after 2001 in comparison to studies published before 2001, 'numbers of potential participants identified' 9/41 (22\%) vs. $0 / 15(0 \%)$ (Fisher's exact test $P=0.094$ ); 'numbers assessed for eligibility' $18 / 41$ (44\%) vs. 4/15 (27\%) (chi-squared $=1.37, \mathrm{df}=1, P=0.24$ ) and 'numbers eligible' $33 / 41$ (80\%) vs. $10 / 15$ (67\%) (chi-squared $=1.18$, $\mathrm{df}=1, P=0.28)$.

Based on the data available, we were able to calculate SPRs for 43 studies. Half of the highest value in the range of proportions for SPR, SDR and IDR was taken as a cutoff value to show studies with participation rates above or below the chosen cutoff value. The SPR amongst studies of PR programmes ranged from 35 to $100 \%$ (that is, a cutoff value of $50 \%$ ), only three $(14 \%)$ studies having less than $50 \%$ SPR. In studies of SM programmes, SPR ranged from 23 to $100 \%$, with four (21\%) studies having less than 50\% SPR. And amongst the three studies of HE programmes, SPR was $43 \%, 73 \%$ and 92\%. Altogether for 43 studies (21 PR, 19 SM, and $3 \mathrm{HE}$ ) the SPR was less than $50 \%$ for only 8 (19\%) studies with 12 (34\%) studies reporting SPR of 100\% (9 PR and 3 SM).

We calculated SDR for all 56 studies and IDR for all studies except for the two before-after studies (here the result of IDR and SDR was the same). Amongst PR studies, study dropout rates ranged from 0 to $59 \%$ (that is, cutoff value of $30 \%)$ with 27 (87\%) studies having SDR of less than or equal to $30 \%$. For studies of SM and HE programmes, the SDR ranged from 0 to $30 \%$ and from 11 to $21 \%$. Overall, 52 (93\%) studies had an SDR of less than or equal to $30 \%$.
The IDR amongst studies of PR programmes ranged from 0 to $54 \%$, 30 (97\%) studies having IDR of less than or equal to $30 \%$. Amongst studies of SM programmes, IDR ranged from 0 to $60 \%$ (that is, a cutoff value of $30 \%$ ), $18 / 20(90 \%)$ studies having less than 30\% IDR. And in studies of HE programmes IDR ranged from 7 to $29 \%$. Overall, IDR for 51/54 (94\%) studies was less than or equal to $30 \%$.

Although we were able to calculate the SDR and IDR, it was difficult to identify and differentiate between the number of participants who were lost to follow-up and participants who discontinued the intervention. We assumed that participants who dropped out of the study also dropped out of the intervention unless papers explicitly stated otherwise.

As SPR was calculated for 43 studies, 31/43 (72\%) studies with SPR of $>50 \%$, had SDR of $\leq 30 \%$. However, no obvious pattern could be deduced as 26/31 (84\%) studies had not reported on participant flow data ('potential participants identified' and/or 'numbers assessed for eligibility) before recruitment (Additional file 2).

In the analysis of study characteristics, there was no evidence for effects of year of publication, study quality, exercise vs. non-exercise, and group vs. individual treatment on participation rate (Table 1). Figure 4 illustrates how year of publication had no effect on participation rate. Confidence intervals for effects were wide, and did not rule out the possibility of a five-fold increase in the odds of participation in exercise vs. non-exercise inter ventions, or a five-fold decrease in group vs. individual interventions.

\section{Discussion}

\section{Principal findings}

Our review provides information on how randomised and non-randomised studies, including before-after studies, of interventions that help to improve SM in patients with COPD, report participant flow and the actual 'participation rates' amongst these studies. The reporting of participant flow amongst studies of the two main interventions (PR and SM) was generally incomplete but better reporting was seen in studies published in and after 2001 (the publication year of the CONSORT

Table 1 Odds ratios for participation according to study characteristics

\begin{tabular}{llll}
\hline Variable & Odds ratio & $(\mathbf{9 5 \%}$ confidence interval $)$ & $\boldsymbol{P}$ \\
\hline Year & 0.99 & $(0.92,1.08)$ & 0.891 \\
Quality score & 0.85 & $(0.65,1.10)$ & 0.215 \\
Exercise intervention & 1.55 & $(0.47,5.07)$ & 0.470 \\
Group intervention & & & 0.506 \\
$\quad$ Individual & 1.00 & - & \\
$\quad$ Combination & 0.17 & $(0.03,0.81)$ & \\
$\quad$ Group & 0.60 & $(0.17,2.11)$ & \\
\hline
\end{tabular}




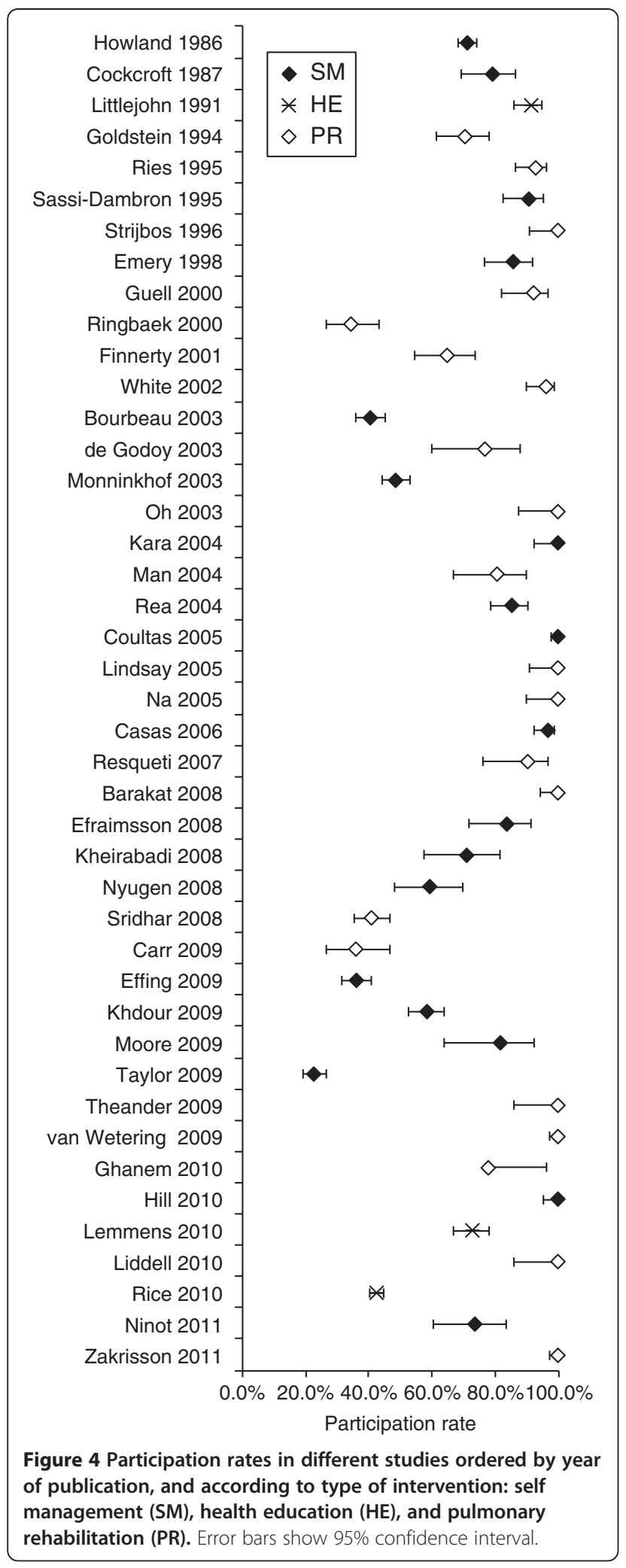

statement). Only $16 \%$ of studies reported 'potential participants identified,' and slightly more than a third (39\%) reported 'numbers assessed for eligibility'. 'Numbers eligible' was better reported amongst studies (77\%) but only seven (13\%) studies reported on all levels of the participant flow before patient recruitment.

The SPR was not calculated for 13 (23\%) studies due to lack of information on 'numbers eligible' for study. The SPR for the remaining 43 studies was higher than expected. Only eight (19\%) studies had an SPR of less than $50 \%$. Another unexpected finding was that $93 \%$ and $94 \%$ of the studies had an SDR and an IDR, respectively, of less than or equal to $30 \%$. However, it was tricky to differentiate between 'numbers lost to follow-up' and 'numbers discontinued intervention'. In addition, 31 (72\%) of 43 studies with SPR of $>50 \%$, had SDR of $\leq 30 \%$ but no obvious pattern could be deduced because of the lack of reporting on participant flow data from 26 (84\%) of the 31 studies.

\section{Comparison with other literature}

Some studies of both pharmacological and nonpharmacological interventions and surgical interventions, have examined reporting of participant flow diagrams (CONSORT statement recommended) including type of information within the diagrams, in published studies identified from a single electronic database [37], in six high-quality [38] and four high-impact journals [39], with most journals endorsing the CONSORT reporting of participant flow [37]. These studies concluded that participant flow was poorly reported. In Toerien's study [38] $40 \%$ of studies failed to report 'numbers assessed for eligibility'. Meanwhile, only 39\% of studies in our review reported 'numbers assessed for eligibility' but our study selection was not based on the quality of the journal. We found low reporting at this level of participant flow in studies perhaps because studies did not think it important to record numbers for external validity, they might not have considered that patients are part of the trial at that level or before randomisation and hence failed to record and report numbers at this level $[38,40]$. It has been acknowledged that studies of PR programmes do not include details or discuss adequately 'numbers assessed for eligibility' nor the refusal rate $[15,25]$.

Regarding reporting 'numbers of potential participants identified' the aforementioned studies did not look at this level (this level is not included in the CONSORT flow diagram). A drawback of strictly designed RCTs may be limited generalisability as the focus is often to have homogenous groups of patients to limit individual variation [41]. A recent literature review [15] of PR programmes looked at reporting of sample selection in studies of PR programmes and only $12 \%$ of studies had 
reported the number of people contacted for the study. In our review, the proportion of studies that reported at this level was slightly higher (16\%). Bjoernshave [15] explained the lack of recording at this level was because people with COPD are not normally recruited from prevalence studies as prevalence of COPD is difficult to estimate and recruitment normally takes place from clinics or outpatient settings. Nevertheless, if we attempt to record the total number of patients registered at a recruitment site 'denominator', this data can be utilised to help generalise the study findings to the target group [35].

Gross's review [39] review found that only $43 \%$ of studies had reported 'numbers eligible'. In our review, more studies had reported this (77\%) perhaps because most of the studies were published in and after 2001. With numbers at this level and numbers recruited we were able to calculate the SPR, SDR and IDR and identify the actual patient 'participation rates' in studies of PR, SM and HE programmes for COPD patients. Only Keating's [19] review has explored patient non-attendance and non-completion, but only in PR programmes and the reported proportions were from a mix of quantitative and qualitative studies. A cutoff value of $20 \%$ for SDR is regarded as acceptable according to a quality assessment checklist [42]. And less than a third (29\%) of studies in our review had a SDR of $>20 \%$, which suggests that most studies in our review would have fulfilled this particular quality criterion. Similarly to other studies $[37,38]$ we too experienced problems in clearly identifying or differentiating between reports of 'numbers lost to follow-up' and 'numbers discontinued intervention'. A distinction needs to be made between these two types of attrition [40] to inform on implementation of interventions.

Based on our findings, previous reports of poor participation and retention in studies of PR and SM programmes [17-20] might not be justified. One explanation could be studies having different definitions for patient participation and thus the method of calculation of participation rates may have differed $[17,26]$ or not having clear definitions making it difficult to identify if the proportions refer to the study or intervention [18]. Recent reviews $[19,38]$ acknowledged that their studies gave varying definitions for 'loss to follow-up' and 'non-completion'. Examples here show discrepancies in reports of participation rates: two studies $[21,22]$ in our review (Additional file 2) had high SPRs of $71 \%$ and 93\%, respectively but Young [25] reported, SPR of $34 \%$ and $36 \%$ for these two studies. On investigation it appears that Young calculated SPR from 'numbers assessed for eligibility' and not 'numbers eligible'; Another study in our review [23] (Additional file 2) had a SDR of $29 \%$ and IDR of $18 \%$ respectively but Sabit [24] reported a dropout rate of $30 \%$ and it is unclear whether the proportion refers to the study or intervention.

\section{Limitations}

We tried to identify numbers reported at each level of the participant flow from effectiveness studies. These studies may have decided to give more importance towards recording and reporting numbers for internal validity - a key feature of strictly designed or high-quality RCTs [41] rather than external validity. This finding is also acknowledged by the new Medical Research Council guidance on evaluation of complex interventions [43]. We need to be cautious of our findings of high participation rates as only a minority of studies reported on all levels of participant flow before recruitment and in some cases $100 \%$ of eligible patients were recruited without providing the whole recruitment picture.

\section{Implications for practice}

Based on our findings of high study participation rates and low dropout rates in research studies of PR, SM and HE programmes, we would strongly endorse the active implementation of $\mathrm{PR}$ and SM programmes in routine care as patients with COPD are participating, attending and completing them. Despite notable evidence of benefit from studies of PR programmes [44] and some benefit from studies of SM programmes [16], in practice these programmes do not seem to be widely implemented or some actively running ones are closing down (Kennedy A. Personal Communication) thus reducing opportunities for patients who are suitable to attend and gain benefits from them. We also recommend that future research studies provide clear definitions when reporting patient participation, enabling a true estimate of patient 'participation rates' and avoiding confusion amongst readers.

To calculate 'participation rates', it is important for studies of PR, SM and HE programmes, to provide more information on patient participant flow. Incomplete reporting of patient recruitment data will affect external validity [15]. It is essential for studies to report these data to help health care professionals interpret the study results and to decide if the results could be applied to their patients $[38,39]$.

Much focus on the implementation of nonpharmacological interventions has resulted in a shift, from conducting explanatory trials to pragmatic trials [41]. One of the features of pragmatic trials is that they tend to recruit a heterogeneous patient group all with the condition of interest to maximise the trial results to usual care settings [45]. To record and report a clear picture of the recruitment process, studies can utilise the checklist provided by extension of the CONSORT statement for reporting pragmatic trials [33]. Gross [39] stressed that studies should at least record and report 'numbers eligible' for recruitment. The addition of several boxes to the CONSORT flow diagram, before and 
after randomisation, has been recommended by Toerin [38], which may help to get a better assessment of generalisability, estimate a true non-participation rate, and to establish a true intervention effect.

\section{Conclusions}

This systematic review has identified the actual levels of participation and dropout rates in research studies evaluating PR, SM and HE programmes for COPD patients. These studies should consider recording and reporting participant flow numbers more completely. Only $19 \%$ of studies had SPR of less than $50 \%$. The SDR and IDR was less than or equal to $30 \%$ in the vast majority of studies. These findings negate previous reports of poor participation and retention in studies of PR and SM programmes. Possible explanations include studies using their own definitions for what constitutes patient participation in both the study and the intervention within the study, or studies, not stating definitions clearly, making it difficult to identify whether proportions reported refer to the study or intervention. Clear and uniform definitions will help to identify a valid estimate of patient participation rates in the study and the intervention and could promote the correct interpretation of studies and the implementation of effective interventions in routine care.

\section{Endnotes}

an five studies 'numbers eligible' was not clearly stated. So to calculate SPR in the five studies 'numbers eligible' were extracted the following way: reasons reported for not taking part in the study, between numbers assessed for eligibility and numbers included in study, were reported as numbers that declined to participate and numbers that were ineligible for the study. The numbers who declined to take part were added to numbers included in the study and were extracted as 'numbers eligible'.

\section{Additional files}

Additional file 1: Search strategy and search terms.

Additional file 2: Participant flow data and participation rates of three interventions.

\section{Abbreviations}

CONSORT: Consolidated Standards of Reporting Trials; COPD: Chronic obstructive pulmonary disease; HE: Health education; IDR: Intervention dropout rate; PR: Pulmonary rehabilitation; PRISMA: Preferred Reporting Items for Systematic Reviews and Meta-analyses; SDR: Study dropout rate; SM: Selfmanagement; SPR: Study participation rate; RCTs: Randomised controlled trials.

\section{Competing interests}

The authors declare that they have no competing interests.

\section{Authors' contributions}

RS participated in the conception and design, data extraction, analysis, interpretation of data and drafting the manuscript. $\mathrm{RH}$ was involved in revising the manuscript critically for important intellectual content. $\mathrm{RH}$ assessed the data extraction. SP and ST were involved in the conception and design and revising the manuscript critically for intellectual content. All authors read and approved the final manuscript.

\section{Acknowledgements}

We are grateful to Professor Khalid Khan, Barts and The London School of Medicine and Dentistry for his helpful comments on drafts of the manuscript.

We would like to thank the authors of the included studies who provided us with further information.

This report is independent research arising from a Doctoral Research Fellowship supported by the National Institute for Health Research. The views expressed in this publication are those of the author(s) and not necessarily those of the NHS, the National Institute for Health Research or the Department of Health.

\section{Funding}

Ratna Sohanpal is funded by a Doctoral Research Fellowship award from the National Institute for Health Research.

\section{Author details}

${ }^{1}$ Centre for Primary Care and Public Health, Blizard Institute, Barts and The London School of Medicine and Dentistry, Queen Mary University of London, 58 Turner Street, London E1 2AB, UK. Unit for Social and Community Psychiatry, Barts and The London School of Medicine and Dentistry, Queen Mary University of London, Newham Centre for Mental Health, London E13 8SP, UK.

Received: 8 August 2012 Accepted: 26 November 2012

Published: 29 December 2012

\section{References}

1. Lomundal BK, Steinsbekk A: Five-year follow-up of a one-year selfmanagement program for patients with COPD. Int J Chron Obstruct Pulmon Dis 2012, 7:87-93.

2. European Respiratory Society: European Lung White Book. Huddersfield: European Respiratory Society Journals Ltd; 2003.

3. Jones R, Gruffydd-Jones K, Pinnock H, Peffers SJ, Lawrence J, Scullion J, et al: Summary of the Consultation on a Strategy for Services for Chronic Obstructive Pulmonary Disease (COPD) in England. Prim Care Respir J 2010, 19:S1-S17.

4. Department of Health/Medical Directorate/Respiratory Team: Consultation on a Strategy for Services for Chronic Obstructive Pulmonary Disease (COPD) in England. London: Department of Health; 2010.

5. Donesky D, Janson SL, Nguyen HQ, Neuhaus J, Neilands TB, Carrieri-Kohlman V: Determinants of frequency, duration, and continuity of home walking in patients with COPD. Geriatr Nurs 2005, 32:178-187.

6. Smith SM, Partridge MR: Getting the rehabilitation message across: emerging barriers and positive health benefits. Eur Respir J 2009, 34:2-4.

7. Labrecque M, Rabhi K, Laurin C, Favreau H, Moullec G, Lavoie K, Julien M: Can a self-management education program for patients with chronic obstructive pulmonary disease improve quality of life? Can Respir J 2011 18:e77-e81.

8. Miles CA, Pincus T, Carnes D, Homer KE, Taylor SJC, Bremner SA, Rahman A, Underwood M: Can we identify how programmes aimed at promoting self-management in musculoskeletal pain work and who benefits? A systematic review of sub-group analysis within RCTs. Eur J Pain 2011, 15:e1-11.

9. Barlow J, Wright C, Sheasby J, Turner A, Hainsworth J: Self-management approaches for people with chronic conditions: a review. Patient Educ and Counse 2002, 48:177-187.

10. IMPRESS: Improving and Integrating Respiratory Services. Principles, Definitions and Standards for Pulmonary Rehabilitation. London; 2008. IMPRESS following consultation with BAOT, ARNS and ACPRC.

11. Bourbeau J: Self-management interventions to improve outcomes in patients suffering from COPD. Expert Rev of Pharmacoecon Outcomes Res 2004, 4:71-77 
12. Curtis RJ, Wenrich MD, Carline JD, Shannon SE, Ambrozy DM, Ramsey PG: Patients' perspectives on physician skill in end-of-life care: differences between patients with COPD, cancer and AIDS. Chest 2002, 122:356-362.

13. Bourbeau J, van der Palen J: Promoting effective self-management programmes to improve COPD. Eur Respir J 2009, 33:461-463.

14. Johnston K, Grimmer-Somers K: Pulmonary rehabilitation: overwhelming evidence but lost in translation? Physiother Can 2010, 62:368-373.

15. Bjoernshave B, Korsgaard J, Nielsen CV: Does pulmonary rehabilitation work in clinical practice? A review on selection and dropout in randomized controlled trials on pulmonary rehabilitation. J Clin Epidemiol 2010, 2:73-83.

16. Effing T, Monninkhof EE, van der Valk $P$, Zielhuis $G G$, Walters $H$, Zwerink M: Self-management education for patients with chronic obstructive pulmonary disease (Review). Cochrane Database Syst Rev 2007, CD002990.

17. Spruit MA, Franssen FM: What to do before pulmonary rehabilitation to improve adherence? Chron Respir Dis 2010, 7:131-133.

18. Harris D, Hayter M, Allender S: Improving the uptake of pulmonary rehabilitation in patients with COPD. Br J Gen Pract 2008, 58:703-710.

19. Keating A, Lee A, Holland AE: What prevents people with chronic obstructive pulmonary disease from attending pulmonary rehabilitation? A systematic review. Chron Respir Dis 2011, 8:89-99.

20. Taylor SJ, Sohanpal R, Bremner SA, Devine A, McDaid D, Fernandez J-L, Griffiths CJ, Eldridge S: Self management support for moderate to severe COPD: a pilot randomised controlled trial. Br J Gen Pract 2012, 62:687-695.

21. Goldstein R, Gort E, Stubbing D, Avendano M, Guyatt G: Randomised controlled trial of respiratory rehabilitation. Lancet 1994, 344:1394-1397.

22. Ries A, Kaplan R, Limberg T, Prewitt L: Effects of pulmonary rehabilitation on physiologic and psychosocial outcomes in patients with chronic obstructive pulmonary disease. Ann Intern Med 1995, 122:823-832.

23. Sewell L, Singh S, Williams J, Collier, Morgan: How long should outpatient pulmonary rehabilitation be? A randomised controlled trial of 4 weeks versus 7 weeks. Thorax 2006, 61:767-771.

24. Sabit R, Griffiths TL, Watkins AJ, Evans W, Bolton CE, Shale DJ, Lewis KE: Predictors of poor attendance at an outpatient pulmonary rehabilitation programme. Respir Med 2008, 102:819-824.

25. Young $P$, Dewse M, Fergusson W, Kolbe J: Respiratory rehabilitation in chronic obstructive pulmonary disease: predictors of nonadherence. Eur Respir J 1999, 13:855-859.

26. Singh S, Smith D, Hyland M, Morgan M: A short outpatient pulmonary rehabilitation programme: immediate and longer-term effects on exercise performance and quality of life. Respir Med 1998, 92:1146-1154.

27. Beswick A, Rees K, Griebsch I, Taylor F, Burke M, West R, Victory J, Brown J, Taylor R, Ebrahim S: Provision, uptake and cost of cardiac rehabilitation programmes: improving services to under-represented group. Health Technol Assess 2004, 8:41

28. Blackstock F, Webster K: Disease-specific health education for COPD: a systematic review of changes in health outcomes. Health Educ Res 2007, 22:703-717.

29. Downs SH, Black N: The feasibility of creating a checklist for the assessment of the methodological quality both of randomised and nonrandomised studies of health care interventions. J Epidemiol Community Health 1998, 52:377-384.

30. Centre for Reviews and Dissemination: Systematic Reviews: CRD's Guidance for Undertaking Reviews in Health Care. York: CRD University of York; 2009 Available at http://www.york.ac.uk/inst/crd/pdf/Systematic_Reviews.pdf

31. Deeks J, Dinnes J, Amico R, Sowden A, Sakarovitch C, Song F, Petticrew M, Altman DG, International Stroke Trial Collaborative Group; European Carotid Surgery Trial Collaborative Group: Evaluating non-randomised intervention studies. Health Technol Assess 2003, 7:1-173.

32. Schulz KF, Altman DG, Moher D, CONSORT Group: CONSORT 2010 Statement: updated guidelines for reporting parallel group randomised trials. PloS Med 2010, 7:e1000251.

33. Zwarenstein M, Treweek S, Gagnier JJ, Altman DG, Tunis S, Haynes B, Oxman AD, Moher D for the CONSORT and Pragmatic Trials in Healthcare (Practihc) group: Improving the reporting of pragmatic trials: an extension of the CONSORT statement. BMJ 2008, 337:a2390.

34. Random.Org [http://www.random.org].

35. Glasgow RE, Magid DJ, Beck A, Ritzwoller D, Estabrooks PA: Practical clinical trials for translating research to practice. Design and Measurement Recommendations. Med Care 2005, 43:551-557.
36. Vollset S: Confidence intervals for a binomial proportion. Stat Med 1993, 12:809-824.

37. Hopewell S, Hirst A, Collins GS, Mallett S, Yu L-M, Altman DG: Reporting of participant flow diagrams in published reports of randomized trials. Trials 2011, 12:253

38. Toerien M, Brookes ST, Metcalfe C, de Salis I, Tomlin Z, Peters TJ, Sterne J, Donovan $\mathrm{J}$ : A review of reporting of participant recruitment and retention in RCTs in six major journals. Trials 2009, 10:52.

39. Gross GP, Mallory R, Helat A, Krumholz HM: Reporting the recruitment process in clinical trials: who are these patients and how did they get there? Ann Intern Med 2002, 137:10-16.

40. Moher D, Hopewell S, Schulz K, Montori V, Gotzsche PC, Devereaux PJ, Elbourne D, Egger M, Altman DG: CONSORT 2010 Explanation and elaboration: updated guidelines for reporting parallel group randomised trials. BMJ 2010, 340:C723.

41. Foster NE, Dziedzic KS, van der Windt DA, Fritz JM, Hay EM: Research priorities for non-pharmacological therapies for common musculoskeletal problems: nationally and internationally agreed recommendations. BMC Musculoskelet Disord 2009, 10:3.

42. Scottish Intercollegiate Guidelines Network: Notes on the use of methodology checklist 2: randomised controlled trials. [http://www.sign. ac.uk/guidelines/fulltext/50/notes2.html].

43. Craig P, Dieppe $P$, Macintyre S, Michie S, Nazareth I, Petticrew M: Developing and evaluating complex interventions an introduction to the new Medical Research Council guidance. In Evidence-Based Public Health: Effectiveness and Efficiency. Edited by Killoran A, Kelly MP. Oxford: Oxford University Press; 2010:185-203.

44. Lacasse Y, Goldstein R, Lasserson T, Martin S: Pulmonary rehabilitation for chronic obstructive pulmonary disease. Cochrane Database of Syst Rev 2006, 18:CD003793.

45. Thorpe KE, Zwarenstein M, Oxman AD, Treweek S, Furberg CD, Altman DG: A pragmatic-explanatory continuum indicator summary (PRECIS): a tool to help trail designers. Studies of pulmonary rehabilitation programmes. J Clin Epidemiol 2009, 62:464-475.

46. Barakat S, Michele G, George P, Nicole V, Guy A: Outpatient pulmonary rehabilitation in patients with chronic obstructive pulmonary disease. Int J Chron Obstruct Pulmon Dis 2008, 3:155-162.

47. Boxall AM, Barclay L, Sayers A, Caplan GA: Managing chronic obstructive pulmonary disease in the community. A randomized controlled trial of home-based pulmonary rehabilitation for elderly housebound patients.

J of Cardpulm Rehabil 2005, 25:378-385.

48. Prince $\mathrm{KL}$, Helm M: Effectiveness of a rehabilitation programme in chronic bronchitis and emphysema. Clin Rehabil 1989, 3:211-214.

49. Goldstein R, Gort E, Stubbing D, Avendano M, Guyatt G: Randomised controlled trial of respiratory rehabilitation. Lancet 1994, 344:13941397.

50. Reardon J, Awad E, Normandin E, Vale F, Clark B, ZuWallack RL: The effect of comprehensive outpatient pulmonary rehabilitation on dyspnea. Chest 1994, 105:1046-1052.

51. Wijkstra PJ, van Altena R, Kraan J, Otten V, Postma DS, Koeter GH: Quality of life in patients with chronic obstructive pulmonary disease improves after rehabilitation at home. Eur Respir J 1994, 7:269-273.

52. Ries A, Kaplan R, Limberg T, Prewitt L: Effects of pulmonary rehabilitation on physiologic and psychosocial outcomes in patients with chronic obstructive pulmonary disease. Ann Intern Med 1995, 122:823-832.

53. Strijbos JH, Postma DS, van Altena R, Gimeno F, Koeter GH: A comparison between an outpatient hospital-based pulmonary rehabilitation program and a home-care pulmonary rehabilitation program in patients with COPD: a follow-up of 18 months. Chest 1996, 109:366-372.

54. Wedzicha JA, Bestall JC, Garrod R, Garnham R, Paul EA, Jones PW: Randomized controlled trial of pulmonary rehabilitation in severe chronic obstructive pulmonary disease patients, stratified with the MRC dyspnoea scale. Eur Respir J 1998, 12:363-369.

55. Ringbaek TJ, Broendum E, Hemmingsen L, Lybeck K, Nielsen D, Andersen C, Lange P: Rehabilitation of patients with chronic obstructive pulmonary disease. Exercise twice a week is not sufficient. Respir Med 2000, 94:150-154.

56. Guell R, Casan P, Belda J, Sangenis M, Morante F, Guyatt GH, Sanchis J: Long-term effects of outpatient rehabilitation of COPD: a randomized trial. Chest 2000, 117:976-983. 
57. Finnerty JP, Keeping I, Bullough I, Jones J: The effectiveness of outpatient pulmonary rehabilitation in chronic lung disease: a randomized controlled trial. Chest 2001, 119:1705-1710.

58. Green $\mathrm{RH}$, Singh SJ, Williams J, Morgan MDL: A randomised controlled trial of four weeks versus seven weeks of pulmonary rehabilitation in chronic obstructive pulmonary disease. Thorax 2001, 56:143-145.

59. White RJ, Rudkin ST, Harrison ST, Day KL, Harvey IM: Pulmonary rehabilitation compared with brief advice given for severe chronic obstructive pulmonary disease. J of Cardpulm Rehabil 2002, 22:338344.

60. de Godoy DV, de Godoy RF: A randomized controlled trial of the effect of psychotherapy on anxiety and depression in chronic obstructive pulmonary disease. Arch Phys Med Rehabil 2003, 84:1154-1157.

61. Oh EG: The effects of home-based pulmonary rehabilitation in patients with chronic lung disease. Int J Nurs Stud 2003, 40:873-879.

62. Man WDC, Polkey MI, Donaldson N, Gray BJ, Moxham J: Community pulmonary rehabilitation after hospitalisation for acute exacerbations of chronic obstructive pulmonary disease: randomised controlled study [with consumer summary]. BMJ 2004, 329:1209-1213.

63. Lindsay M, Lee A, Chan K, Poon P, Han LK, Wong WC, Wong S: Does pulmonary rehabilitation give additional benefit over tiotropium therapy in primary care management of chronic obstructive pulmonary disease? Randomized controlled clinical trial in Hong Kong Chinese. J Clin Pharm Ther 2005, 30:567-573.

64. Na JO, Kim DS, Yoon SH, Jegal YJ, Kim WS, Kim ES, Kim MW: A simple and easy home-based pulmonary rehabilitation programme for patients with chronic lung diseases. Monaldi Arch Chest Dis 2005, 63:30-36.

65. Sewell L, Singh S, Williams J, Collier M: How long should outpatient pulmonary rehabilitation be? A randomised controlled trial of 4 weeks versus 7 weeks. Thorax 2006, 61:767-771.

66. Guell R, Resqueti V, Sangenis M, Morante F, Martorell B, Casan P, Morante F, Guyatt $\mathrm{GH}$, Sanchis J: Impact of pulmonary rehabilitation on psychosocial morbidity in patients with severe COPD. Chest 2006, 129:899-904.

67. Resqueti V, Gorostiza A, Galdiz JB, Lopez de Santa Maria E: Casan Clara P, Guell Rous R: Benefits of a home-based pulmonary rehabilitation program for patients with severe chronic obstructive pulmonary disease. Arch Bronconeumol 2007, 43:599-604.

68. Karapolat H, Atasever A, Atamaz F, Kirazli Y, Elmas F, Erdinc E: Do the benefits gained using a short-term pulmonary rehabilitation program remain in COPD patients after participation? Lung 2007, 185:221-225.

69. Sridhar M, Taylor R, Dawson S, Roberts NJ, Partridge MR: A nurse-led intermediate care package in patients who have been hospitalised with an acute exacerbation of chronic obstructive pulmonary disease. Thorax 2008, 63:194-200.

70. Carr SJ, Hill K, Brooks D, Goldstein RS: Pulmonary rehabilitation after acute exacerbation of chronic obstructive pulmonary disease in patients who previously completed a pulmonary rehabilitation program. J Cardiopulm Rehabil Prev 2009, 29:318-324.

71. Theander K, Jakobsson P, Jorgensen N, Unosson M: Effects of pulmonary rehabilitation on fatigue, functional status and health perceptions in patients with chronic obstructive pulmonary disease: a randomized controlled trial. Clin Rehabil 2009, 23:125-136.

72. van Wetering CR, Hoogendoorn M, Mol SJM, Rutten-van-Mölken MPMH, Schols AM: Short- and long-term efficacy pf a community-based COPD management program in less advanced COPD: a randomized controlled trial. Thorax 2010, 65:7-13.

73. Ghanem M, Elaal EA, Mehany M, Tolba K: Home-based pulmonary rehabilitation program: Effect on exercise tolerance and quality of life in chronic obstructive pulmonary disease patients. Ann Thorac Med 2010, 5:18-25.

74. Liddell F, Webber J: Pulmonary rehabilitation for chronic obstructive pulmonary disease: a pilot study evaluating a once-weekly versus twiceweekly supervised programme. Physiotherapy 2010, 96:68-74.

75. Seymour JM, Moore L, Jolley CJ, Ward K, Creasey J, Steier JS, Yung B, Man WD, Hart N, Polkey MI, Moxham J: Outpatient pulmonary rehabilitation following acute exacerbations of COPD. Thorax 2010, 65:423-428.

76. Zakrisson A-B, Engfeldt P, Hagglund D, Odencrants S, Hasselgren M, Arne $M$, Theander $K$ : Nurse-led multidisciplinary programme for patients with COPD in primary health care: a controlled trial. Studies of self-management programmes. Prim Care Respir J 2011, 20:427-433.
77. Howland J, Nelson EC, Barlow PB, McHugo G, Meier FA, Brent P, LaserWolston N, Parker HW: Chronic obstructive airway disease. Impact of health education. Chest 1986, 90:233-238.

78. Cockcroft A, Bagnall P, Heslop A, Andersson N, Heaton R, Batsone J, Allen J, Spencer $P$, Guz A: Controlled trial of respiratory health worker visiting patients with chronic respiratory disability. BMJ 1987, 294:225-228.

79. Sassi-Dambron DE, Eakin EG, Ries AL, Kaplan RM: Treatment of dyspnea in COPD. A controlled clinical trial of dyspnea management strategies. Chest 1995, 107:724-729.

80. Zimmerman BW, Brown ST, Bowman JM: A self-management program for chronic obstructive pulmonary disease: relationship to dyspnea and selfefficacy. Rehabil Nurs 1996, 21:253-257.

81. Emery CF, Schein RL, Hauck ER, Maclntyre NR: Psychological and cognitive outcomes of a randomized trial of exercise among patients with chronic obstructive pulmonary disease. Health Psychol 1998, 17:232-240.

82. Bourbeau J, Julien M, Maltais F, Rouleau M, Beaupre A, Begin R, Renzi P, Nault D, Borycki E, Schwartzman K, Singh R, Collet JP, Chronic Obstructive Pulmonary Disease axis of the Respiratory Network Fonds de la Recherche en Santé du Québec: Reduction of hospital utilization in patients with chronic obstructive pulmonary disease: a disease-specific selfmanagement intervention. Arch Intern Med 2003, 163:585-591.

83. Monninkhof E, Van DV, Der PJV, Van HC, Zielhuis G: Effects of a comprehensive self-management programme in patients with chronic obstructive pulmonary disease. Eur Respir J 2003, 22:815-820.

84. Rea H, McAuley S, Stewart A, Lamont C, Roseman P, Didsbury P: A chronic disease management programme can reduce days in hospital for patients with chronic obstructive pulmonary disease. Internal Medicine Journal 2004, 34:608-614.

85. Kara M, Asti T: Effect of education on self-efficacy of Turkish patients with chronic obstructive pulmonary disease. Patient Educ Couns 2004, 55:114-120.

86. Coultas D, Frederick J, Barnett B, Singh G, Wludyka P: A randomized trial of two types of nurse-assisted home care for patients with COPD. Chest 2005, 128:2017-2024.

87. Casas A, Troosters T, Garcia-Aymerich J, Roca J, Hernandez C, Alonso A, del Pozo F, de Toledo P, Antó JM, Rodríguez-Roisín R, Decramer M, members of the CHRONIC Project: Integrated care prevents hospitalisations for exacerbations in COPD patients. Eur Respir J 2006, 28:123-130

88. Nguyen HQ, Donesky-Cuenco D, Wolpin S, Reinke LF, Benditt JO, Paul SM, Carrieri-Kohlman V: Randomized controlled trial of an internet-based versus face-to-face dyspnea self-management program for patients with chronic obstructive pulmonary disease: pilot study. J Med Internet Res 2008, 10:e9.

89. Kheirabadi GR, Keypour M, Attaran N, Bagherian R, Maracy MR: Effect of add-on "Self management and behavior modification" education on severity of COPD. Tanaffos 2008, 7:23-30.

90. Effing $T$, Kerstjens $H$, Van DV, Zielhuis G, der PJ V: (Cost)-effectiveness of self-treatment of exacerbations on the severity of exacerbations in patients with COPD: the COPE II study. Thorax 2009, 64:956-962.

91. Efraimsson EO, Hillervik C, Ehrenberg A: Effects of COPD self-care management education at a nurse-led primary health care clinic. Scand J Caring Sci 2008, 22:178-185.

92. Khdour MR, Kidney JC, Smyth BM, McElnay JC: Clinical pharmacy-led disease and medicine management programme for patients with COPD. Br J Clin Pharmacol 2009, 68:588-598.

93. Moore J, Fiddler H, Seymour J, Grant A, Jolley C, Johnson L, Moxham J: Effect of a home exercise video programme in patients with chronic obstructive pulmonary disease. J Rehabil Med 2009, 41:195-200.

94. Koff PB, Jones RH, Cashman JM, Voelkel NF, Vandivier RW: Proactive integrated care improves quality of life in patients with COPD. Eur Respir J 2009, 33:1031-1038.

95. Hill K, Mangovski-Alzamora S, Blouin M, Guyatt G, Heels-Ansdell D, Bragaglia P, Tamari I, Jones K, Goldstein R: Disease-specific education in the primary care setting increases the knowledge of people with chronic obstructive pulmonary disease: a randomized controlled trial. Patient Educ Couns 2010, 81:14-18.

96. Ninot G, Moullec G, Picot MC, Jaussent A, Hayot M, Desplan M, Brun JF, Mercier J, Prefaut C: Cost-saving effect of supervised exercise associated to COPD self-management education program. Respir Med 2011, 105:377-385. 
97. Taylor SJC, Sohanpal R, Bremner S, Devine A, McDaid D, Fernandez JL, Griffiths CJ: Self management support for moderate to severe COPD: a pilot randomised controlled trial. Studies of health education programmes. Br J Gen Pract 2012, 62:e687-e695.

98. Lemmens KMM, Nieboer AP, Rutten-Van Molken MPMH, van Schayck CP, Asin JD, Dirven JAM, Huijsman R: Application of a theoretical model to evaluate COPD disease management. BMC Health Serv Res 2010, 10:81.

99. Littlejohns P, Baveystock CM, Parnell H, Jones PW: Randomised controlled trial of the effectiveness of a respiratory health worker in reducing impairment, disability, and handicap due to chronic airflow limitation. Thorax 1991, 46:559-564.

100. Petty TL, Dempsey EC, Collins T, Pluss W, Lipkus I, Cutter GR, Chalmers R, Mitchell A, Weil KC: Impact of customized videotape education on quality of life in patients with chronic obstructive pulmonary disease. J Cardiopulm Rehabil 2006, 26:112-117.

101. Rice KL, Dewan N, Bloomfield HE, Grill J, Schult TM, Nelson DB, Kumari S, Thomas M, Geist LJ, Beaner C, Caldwell M, Niewoehner DE: Disease management program for chronic obstructive pulmonary disease: a randomized controlled trial. Am J Respir Crit Care Med 2010, 182:890-896.

doi:10.1186/2046-4053-1-66

Cite this article as: Sohanpal et al:: Reporting participation rates in studies of non-pharmacological interventions for patients with chronic obstructive pulmonary disease: a systematic review. Systematic Reviews 2012 1:66.

\section{Submit your next manuscript to BioMed Central and take full advantage of:}

- Convenient online submission

- Thorough peer review

- No space constraints or color figure charges

- Immediate publication on acceptance

- Inclusion in PubMed, CAS, Scopus and Google Scholar

- Research which is freely available for redistribution 